\title{
Transport Characteristics of Tryptanthrin and its Inhibitory Effect on P-gp and MRP2 in Caco-2 Cells
}

\author{
Xingang Zhu ${ }^{1, \dagger}$, Xuelian Zhang ${ }^{1, \dagger}$, Guo $\mathrm{Ma}^{2}$, Junkai Yan ${ }^{1}$, Honghai Wang ${ }^{1}$, Qing Yang ${ }^{1}$ \\ 1. School of Life Sciences, Fudan University, Handan Road, Shanghai 200433, China \\ 2. School of Pharmacy, Fudan University, Zhangheng Road 826, Shanghai 201203, China \\ Corresponding Author: Qing Yang, Ph.D, School of Life Sciences, Fudan University, Handan Road 220, Shanghai, China; E-mail
}

\begin{abstract}
Purpose. Tryptanthrin, an indole quinazoline alkaloid with multiple medical activities, has been recently under preclinical development as an anti-tuberculosis and anti-tumor drug. The aims of this study are to characterize the intestinal transport of tryptanthrin in Caco-2 cells, to determine whether P-glycoprotein (P-gp) and multidrug resistance-associated protein 2 (MRP2) are involved in this issue, and to evaluate the potential influence of tryptanthrin on the function of P-gp and MRP2. Methods. Transport assays of tryptanthrin were performed in Caco-2 monolayers with or without the supplement of P-gp and MRP2 inhibitors. Transport assays of P-gp and MRP2 substrates were also performed in the presence of tryptanthrin. The effect of tryptanthrin on the expression of P-gp and MRP2 was analyzed by reverse transcriptase-PCR. Results. Both absorption and secretion of tryptanthrin were concentration-independent at a low concentration range of $0.8-20 \mu \mathrm{M}$. The apparent permeability ( $\mathrm{Papp}$ ) for the apical (AP) to basolateral (BL) was $6.138 \pm 0.291 \times 10^{-5}$. The ratio of $\mathrm{P}_{\text {app }(\mathrm{BL} \rightarrow \mathrm{AP})}$ to $\mathrm{P}_{\text {app }(\mathrm{AP} \rightarrow \mathrm{BL})}$ was 0.77 , suggesting greater permeability in the absorptive direction. Both the P-gp inhibitor, verapamil, and the MRP2 inhibitor, glibenclamide, didn't affect the efflux transport of tryptanthrin. The efflux transport of the P-gp substrate, digoxin, and the MRP2 substrate, pravastatin sodium, decreased when tryptanthrin was present. However, tryptanthrin didn't change the expression of P-gp and MRP2. Conclusions. Tryptanthrin was well absorbed across the Caco-2 monolayers, and its transepithelial transports were dominated by passive diffusion. Tryptanthrin was not a substrate, but a potential inhibitor of P-gp and MRP2.
\end{abstract}

This article is open to POST-PUBLICATION REVIEW. Registered readers (see "For Readers") may comment by clicking on ABSTRACT on the issue's contents page.

\section{INTRODUCTION}

Tryptanthrin (indolo[2,1-b]quinazolin-6,12-dione, Figure 1) is a natural product of the Chinese medicinal plant, Strobilanthes cusia. It has generated interest as a potential therapeutic agent because of its simple structure convenient to synthesis and broad spectrum of biological activities. Some of these biological properties of tryptanthrin include antifungal activity against various Trichophyton, Microsporum, and Epidermophyron species (1), anti-growth of Leishmania donovani, Trypanosoma brucei, and Plasmodium falciparum (2-4), and anti-inflammation via inhibiting cyclooxygenase-2 activity or down-regulating the expression of nitric oxide synthase (5-7). Particularly, the in vitro antitumor activity of tryptanthrin has been observed in a number of cancer cell lines, including leukemia U937, breast MCF-7, glioma U251, colon SW620, and lung H522 (8-9), and the in vivo antitumor activity of tryptanthrin has been observed as well (10). Above all, the most attractive and important biological activity of tryptanthrin is its anti-tuberculosis property. It has been demonstrated that tryptanthrin is more potent against Mycobacterium tuberculosis [minimum inhibitory concentration $(\mathrm{MIC})=1 \mathrm{mg} / \mathrm{L}]$, in Bactec studies, than against $M$. smegmatis $(4 \mathrm{mg} / \mathrm{L})$, in agar-dilution work (11). Furthermore, the previous study with a panel of multiple drug-resistant (MDR) tuberculosis strains showed that tryptanthrin retained its potency $(0.5-1.0 \mathrm{mg} / \mathrm{L})$; while isoniazid decreased its activity from 4.0 to $16.0 \mathrm{mg} / \mathrm{L} \mathrm{(11).}$ Taken together, these reports reveal that tryptanthrin is a potential agent against tuberculosis, particular MDR-tuberculosis.

Corresponding Author: Qing Yang, Ph.D, School of Life Sciences, Fudan University, Handan Road 220, Shanghai, China; E-mail address: yangqing68@fudan.edu.cn. X. Zhu and $\mathrm{X}$. Zhang contributed equally to this paper 


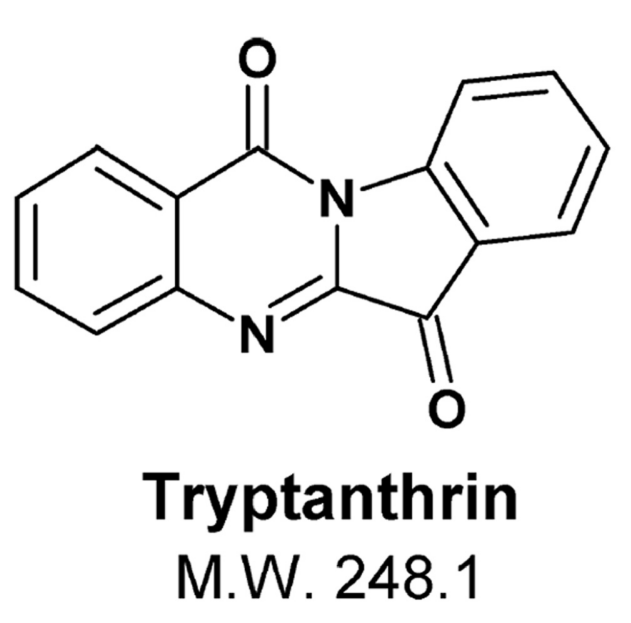

Figure 1. Structure of tryptanthrin ( indolo - [2,1-b] quinazoline - 6, 12 - dione)

As a potential drug candidate with multiple medical activities, the pharmacological actions of tryptanthrin have been widely studied; but its pharmacokinetic properties have rarely been reported. The preclinical trials are currently investigating the efficacy of tryptanthrin as an anti-tuberculosis and anti-tumor drug (12-13). Understanding the absorption and transport of drug candidates is a critical step in the process of drug development. Therefore, the detailed information regarding intestinal absorption and secretion of tryptanthrin are of specific importance and should be investigated. In this study, Caco- 2 cells (human colorectal adenocarcinoma cell line), a widely accepted in vitro model for drug absorption and metabolism studies (14), were used to characterize the intestinal transport of tryptanthrin.

It is well known that ATP-driven efflux pumps, such as P-glycoprotein (P-gp encoded by MDR1) and multidrug resistance-associated protein 2 (MRP2), play significant roles in drug absorption, distribution, metabolism and excretion processes. In the oral absorption level, these transporters are present on the apical brush border membrane of gut enterocytes and actively cause efflux of drugs from the gut epithelial cells back into the intestinal lumen. Up to now, it is still unclear whether P-gp and MRP2 participate in the transport of tryptanthrin in Caco-2 cells. On the other hand, it has been reported that tryptanthrin downregulates the expression of the MDR1 gene in MCF-7 cells (human breast cancer cell line) and thus enhances the cytotoxicity of doxorubicin against MCF-7 cells due to the uptake of doxorubicin increased in the presence of tryptanthrin (15). Consequently, determining whether tryptanthrin directly affects the function of P-gp or MRP2 also is of particular importance.

In this study, using Caco-2 cells, the intestinal transport profile of tryptanthrin was studied in a low concentration range and the type of tryptanthrin transport was identified. In addition, the possible participation of P-gp and MRP2 in tryptanthrin transport was examined with the supplement of transporter inhibitors. Furthermore, the effect of tryptanthrin on the function of P-gp and MRP2 was also evaluated.

\section{METHODS}

\section{Materials}

Tryptanthrin was generously given by Prof. Jianli Liu from The College of Life Sciences, Northwest University, Xi'an, China. Digoxin and verapamil were purchased from Sigma Chemical Co. (St. Louis, MO, USA). Pravastatin sodium was purchased from Beta Pharma Inc. Co., Ltd. (Shanghai, China). Glibenclamide was purchased from Dongfang Pharma Technology Inc. (Shanghai, China). Hank's balanced salt solution (HBSS), trypsin-EDTA, Dulbecco's modified Eagle's medium (DMEM), non-essential amino acid solution, and penicillin-streptomycin solution were purchased from Gibco Laboratories (Invitrogen Co, Grand Island, NY, USA). Heat-inactivated fetal bovine serum (FBS) was purchased from Shanghai Al-Amin Bio-tech Co., Ltd. (Shanghai, China). TRIzol Reagent was purchased from the Invitrogen Corporation (Carlsbad, CA, USA). Acetonitrile and methanol (HPLC grade) were from Fisher Scientific Co., Ltd. (Fair Lawn, New Jersey, USA). All other chemicals used in the study were at least of analytical grade.

\section{Cell Culture}

The Caco-2 cell line was obtained from the American Type Culture Collection (Rockbille, MD, USA). Cells were routinely grown in $75 \mathrm{~cm}^{2}$ plastic culture flasks (Becton Dickinson, Franklin Lakes, NJ, USA) in DMEM supplemented with $10 \%(\mathrm{v} / \mathrm{v})$ FBS, $1 \%(\mathrm{v} / \mathrm{v})$ non-essential amino acid solution, and $1 \%(\mathrm{v} / \mathrm{v})$ penicillin-streptomycin solution at $37{ }^{\circ} \mathrm{C}$ under a $5 \% \quad \mathrm{CO}_{2}$ atmosphere with $90 \%$ relative humidity. The medium was replaced every 2-3 days after incubation. Cells were passaged every 5 days approximately between $70 \%-80 \%$ confluence at a split ratio of $1: 5$, using $0.25 \%$ 
trypsin and $0.02 \%$ EDTA. For the transport experiments, the cells of passages between 32 and 40 were seeded at a density of $5 \times 10^{4}$ cells $/ \mathrm{cm}^{2}$ onto permeable polycarbonate inserts $\left(0.6 \mathrm{~cm}^{2}, 0.45\right.$ $\mu \mathrm{m}$ pore size, Millipore, USA) in 6-well tissue culture plates (NUNC, Roskilde, Denmark). Media in the culture plates were changed every two days for the first week post seeding and was then replaced daily. Testing cell monolayer integrity on Transwell inserts was done by measuring transepithelial electrical resistance (TEER) across the cell monolayer or by measuring the amount of a nontransportable fluorescent compound fluorescein that leaks from the apical chamber between the cells down into the basolateral chamber. When the cell monolayers displayed that the TEER values were above $600 \Omega \cdot \mathrm{cm}^{2}$ and the permeability of fluorescein was less than $0.5 \times 10^{-6} \mathrm{~cm} / \mathrm{s}$, the monolayers were considered not leaky. In our culture condition, Caco- 2 monolayers, post seeding between 21 and 24 days, usually were available for the experiments. To ensure the integrity of the monolayers, the TEER value was measured again right before the transport assay.

\section{Transport Studies in Caco-2 Cell Monolayers}

Transport of tryptanthrin across the Caco- 2 cell monolayers was studied using monolayers 21-24 days post seeding. Before the experiments, the monolayers were washed twice with HBSS $(\mathrm{pH}$ 7.4). After washing, the monolayers were preincubated at $37{ }^{\circ} \mathrm{C}$ for $20 \mathrm{~min}$, and TEER was measured. HBSS solution on both sides of the cell monolayers was then removed by aspiration.

For measurement of the apical (AP) to basolateral (BL) transport, $400 \mu \mathrm{L}$ of HBSS containing tryptanthrin $(0.8-20 \mu \mathrm{M})$ was added to the AP side and $600 \mu \mathrm{L}$ of HBSS without the drug was added to the BL side. For measurement of the BL to AP transport, $600 \mu \mathrm{L}$ of HBSS containing tryptanthrin $(0.8-20 \mu \mathrm{M})$ was added to the BL side and $400 \mu \mathrm{L}$ of HBSS without the drug was added to the AP side. Tryptanthrin solutions were freshly prepared dissolving it in dimethyl sulfoxide (DMSO). The final concentration of DMSO in the HBSS was below $0.1 \%$. The monolayers were incubated at $37{ }^{\circ} \mathrm{C}$, and then placed in a shaker at $50 \mathrm{rpm}$ during the transport process to minimize the influence of the aqueous boundary layer. Samples were taken from the receptor chamber every $20 \mathrm{~min}$ for 2 hours, followed by an immediate replacement of the same volume of prewarmed fresh HBSS.

Tryptanthrin was evaluated for its potential as a substrate of P-gp or MRP2 in Caco-2 cell monolayers. The transport assay of tryptanthrin was performed with the addition of the P-gp inhibitor, verapamil, and the MRP2 inhibitor, glibenclamide. The absorption and efflux transport apparent permeability $\left(\mathrm{P}_{\text {app }}\right)$ of tryptanthrin were determined at a fixed substrate concentration $(4 \mu \mathrm{M})$ and inhibitor concentration $(100 \mu \mathrm{M})$.

To evaluate the potential effect of tryptanthrin on P-gp and MRP2 function, the efflux transport assays of digoxin $(5 \mu \mathrm{M})$ and pravastatin sodium $(0.5 \mathrm{mM})$, selective substrates of P-gp and MRP2, respectively, were performed in the presence of tryptanthrin $(4 \mu \mathrm{M})$. The efflux $\mathrm{P}_{\text {app }}$ of both digoxin and pravastatin sodium were determined.

\section{Reverse Transcription-polymerase Chain Reaction (RT-PCR) Analysis of MDR1 and MRP2 Gene Expression}

Caco-2 monolayers ready for the transport assay were treated with tryptanthrin $(4 \mu \mathrm{M})$ or DMSO $(0.1 \%, \mathrm{v} / \mathrm{v})$ as vehicle control. Untreated Caco-2 monolayers were used as the control. After exposure to tryptanthrin for $2 \mathrm{~h}$ or $4 \mathrm{~h}$, Caco- 2 cells were washed with ice-cold HBSS $(\mathrm{pH}$ 7.4) and harvested.

Total mRNA was extracted using TRIzol reagent according to the manufacturer's protocol and quantified by UV-visible Recording spectrophotometer (Shimadzu, Kyoto, Japan). The cDNA were synthesized using M-MuLV reverse transcriptase with Oligo $(\mathrm{dT})_{18}$ random primer from $1 \mu \mathrm{g}$ total mRNA. The primers (Invitrogen, Carlsbad, CA, USA) for MDR1 were MDR1-F (5'-TGA CTA CCA GGC TCG CCA ATG AT-3') and MDR1-R, (5'-TGT GCC ACC AAG TAG GCT CCA AA-3'). The primers for MRP2 were MRP2-F (5'-AGG TTT GCC AGT TAT CCG TG-3') and MRP2-R, (5'-AAC AAA GCC AAC AGT GTC CC-3'). The primers for GAPDH were as follows: GAPDH-F (5'-ATG GTG AAG GTC GG-3') and GAPDH-R (5'-TTA CTC CTG GAG GCC ATG T-3'). GAPDH was used as the internal control. PCR was performed in a S1000 Thermal Cycler system (Bio-Rad, Richmond, CA, USA). Samples were amplified with a precycling hold at $96{ }^{\circ} \mathrm{C}$ for $5 \mathrm{~min}$, followed by 31 cycles of denaturation at $96{ }^{\circ} \mathrm{C}$ for $1 \mathrm{~min}, 56{ }^{\circ} \mathrm{C}$ annealing for $1 \mathrm{~min}$, and extension at $72{ }^{\circ} \mathrm{C}$ for $1 \mathrm{~min}$. PCR products were separated on $1.5 \%$ agarose gel and photographed with a gel analysis system. 


\section{High-performance Liquid Chromatography (HPLC) Analysis of the Samples}

HPLC analysis was carried out using a LC-10AVP HPLC system equipped with a LC-10AT pump and a SPD-10A UV detector (Shimadzu, Kyoto, Japan). The detection wavelength was $254 \mathrm{~nm}$. HPLC analysis of the samples was performed using a YMC ODS $\mathrm{C}_{18}$ column $(150 \pm 4.2 \mathrm{~mm}$ i.d., $5 \mu \mathrm{m}$, Japan) preceded by a $\mathrm{C}_{18}$ guard column (Dikma, China). The column temperature was maintained at $35{ }^{\circ} \mathrm{C}$ at a flow rate of $1 \mathrm{~mL} / \mathrm{min}$. The mobile phase was a mixture of acetonitrile $/ 2 \%$ ethanoic acid $(40: 60, \mathrm{v} / \mathrm{v})$. The retention time of tryptanthrin was $5.5 \mathrm{~min}$. Determination of digoxin and pravastatin sodium was performed with HPLC as reported (16-17).

The samples were analyzed by the modified reversed-phase HPLC described previously. After centrifugation at $12,000 \mathrm{rpm}$ for $5 \mathrm{~min}, 20 \mu \mathrm{L}$ of the supernatant of the samples obtained from the Caco- 2 cells transport assays was directly analyzed with HPLC. The standard curve of tryptanthrin was linear within the range $0.04-20 \mu \mathrm{M}\left(\mathrm{r}^{2}=0.9999\right)$. The standard curve of digoxin was linear within the range $0.5-50 \mu \mathrm{M}\left(\mathrm{r}^{2}=0.9997\right)$. The standard curve of pravastatin sodium was linear within the range $12-1200 \mu \mathrm{M}\left(\mathrm{r}^{2}=0.9999\right)$.

\section{Calculation and Data Analysis}

The $\mathrm{P}_{\text {app }}$ coefficients were calculated for the directional flux studies according to Equation 1:

$$
P_{a p p}=\frac{(d Q / d t)}{\left(A \times C_{0}\right)} \quad \text { Equation } 1
$$

where $\mathrm{dQ} / \mathrm{dt}(\mu \mathrm{g} / \mathrm{min})$ is the drug permeation rate, $\mathrm{A}$ is the cross-sectional area $\left(0.6 \mathrm{~cm}^{2}\right)$, and $\mathrm{C}_{0}$ $(\mu \mathrm{g} / \mathrm{mL})$ is the initial drug concentration in the donor compartment at $\mathrm{t}=0$ min.

The net efflux of a test compound is assessed by calculating the ratio of $\mathrm{P}_{\text {app }}$ from $\mathrm{BL}$ to $\mathrm{AP}$ versus $\mathrm{P}_{\text {app }}$ from $\mathrm{AP}$ to $\mathrm{BL}\left(\mathrm{P}_{\text {app }(\mathrm{BL} \rightarrow \mathrm{AP})} / \mathrm{P}_{\text {app }(\mathrm{AP} \rightarrow \mathrm{BL})}\right)$. A ratio substantially greater than 1.0 indicates a net efflux of the drug; otherwise, the absorptive transport is preponderant.

\section{Statistical Analysis}

Results are given as mean \pm S.D. Statistical significance was tested by two-tailed Student's t-test. Statistical significance was set to $P<0.05$.

\section{RESULTS}

Absorptive and Efflux Transport of Tryptanthrin Across Caco-2 Cells

Due to the poor solubility of tryptanthrin in HBSS, the absorptive and efflux transport of tryptanthrin were examined over a low concentration range $(0.8-20 \mu \mathrm{M})$. As indicated in Table 1 , both the absorptive $\mathrm{P}_{\text {app }(\mathrm{AP} \rightarrow \mathrm{BL})}$ and the secretory $\mathrm{P}_{\text {app }(\mathrm{BL} \rightarrow \mathrm{AP})}$ of tryptanthrin had no significant change at three different concentrations $(0.8,4,20 \mu \mathrm{M})$. These results suggested that the transport of tryptanthrin was concentration-independent in this concentration range. The efflux ratios, calculated from the permeability of $\mathrm{BL}$ to $\mathrm{AP}$ versus the permeability of AP to BL, were all below 1 in the concentration range of $0.8-20 \mu \mathrm{M}$, suggesting that the absorptive transport of tryptanthrin was preponderant.

Effects of P-gp and MRP2 Inhibitors on the Permeation of Tryptanthrin Across Caco-2 Cell Monolayers

To determine the effect of P-gp and MRP2 inhibitors on tryptanthrin, the transport assays of tryptanthrin $(4 \mu \mathrm{M})$, tryptanthrin $(4 \mu \mathrm{M})+$ verapamil $(100 \mu \mathrm{M})$ and tryptanthrin $(4 \mu \mathrm{M})+$ glibenclamide $(100 \mu \mathrm{M})$ were carried out respectively.

The $\mathrm{P}_{\text {app }}$ coefficients of tryptanthrin across Caco-2 cell monolayers in the $\mathrm{AP} \rightarrow \mathrm{BL}$ and $\mathrm{BL} \rightarrow \mathrm{AP}$ directions, in the presence vs. absence of verapamil or glibenclamide, are presented in Table 2. In the efflux direction $(\mathrm{BL} \rightarrow \mathrm{AP})$, the $\mathrm{P}_{\text {app }}$ of tryptanthrin remained almost constant when verapamil $(100 \mu \mathrm{M})$ or glibenclamide $(100 \mu \mathrm{M})$ was added to both sides of Caco-2 cell monolayers. These results suggested that the efflux transport of tryptanthrin was not affected by both P-gp and MRP2 inhibitors, in the other word, neither P-gp nor MRP2 participated in the efflux transport of tryptanthrin. In the uptake direction $(\mathrm{AP} \rightarrow \mathrm{BL})$, the $\mathrm{P}_{\text {app }}$ of tryptanthrin was hardly influenced by verapamil, which means that the P-gp did not affect the uptake transport of tryptanthrin. But the $\mathrm{P}_{\text {app }}$ $(\mathrm{AP} \rightarrow \mathrm{BL})$ of tryptanthrin was significantly decreased when glibenclamide was added $(P<0.01)$. Nevertheless, this result cannot lead to the conclusion that the MRP2 was involved in the uptake of tryptanthrin because glibenclamide is not a specific inhibitor of the MRP2 and may inhibit the function of other uptake transporters rather than that of the MRP2 (18). 
To better understand the performance of tryptanthrin in the process of transport assays with or without presence of transporter inhibitors, the samples were taken at each desired time point over the period of $2 \mathrm{~h}$. Figure 2 showed the results of these time course assays. The transport of tryptanthrin in both uptake (Fig 2A) and efflux directions (Fig 2B) was linearly increased over the time regardless in the presence or absence of the inhibitors. At each desired time point, the efflux permeation of tryptanthrin (Fig 2B) was not significantly affected by either verapamil or glibenclamide. However, the uptake permeation of tryptanthrin (Fig 2A) was substantially decreased in the presence of glibenclamide $(P<0.05)$, but not of verapamil, at the late assay period (80-120 min). These results are consistent with the end point of transport assays shown in Table 2.

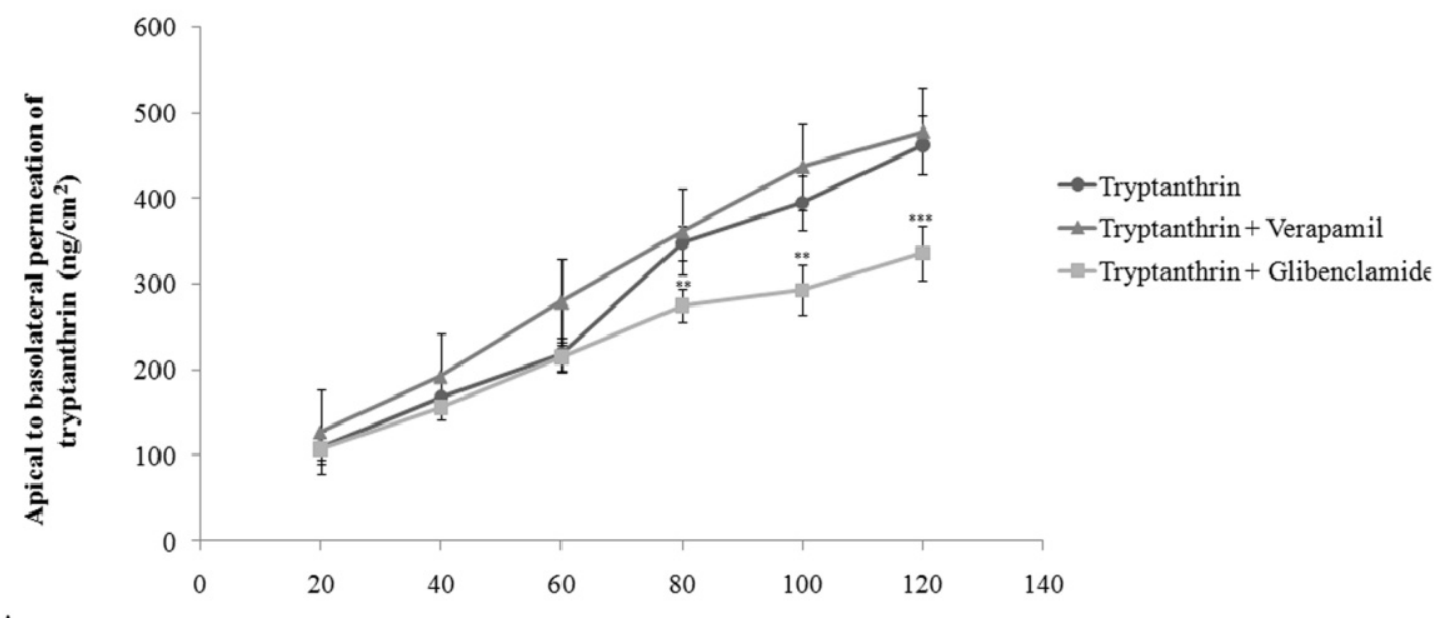

A

Time (min)

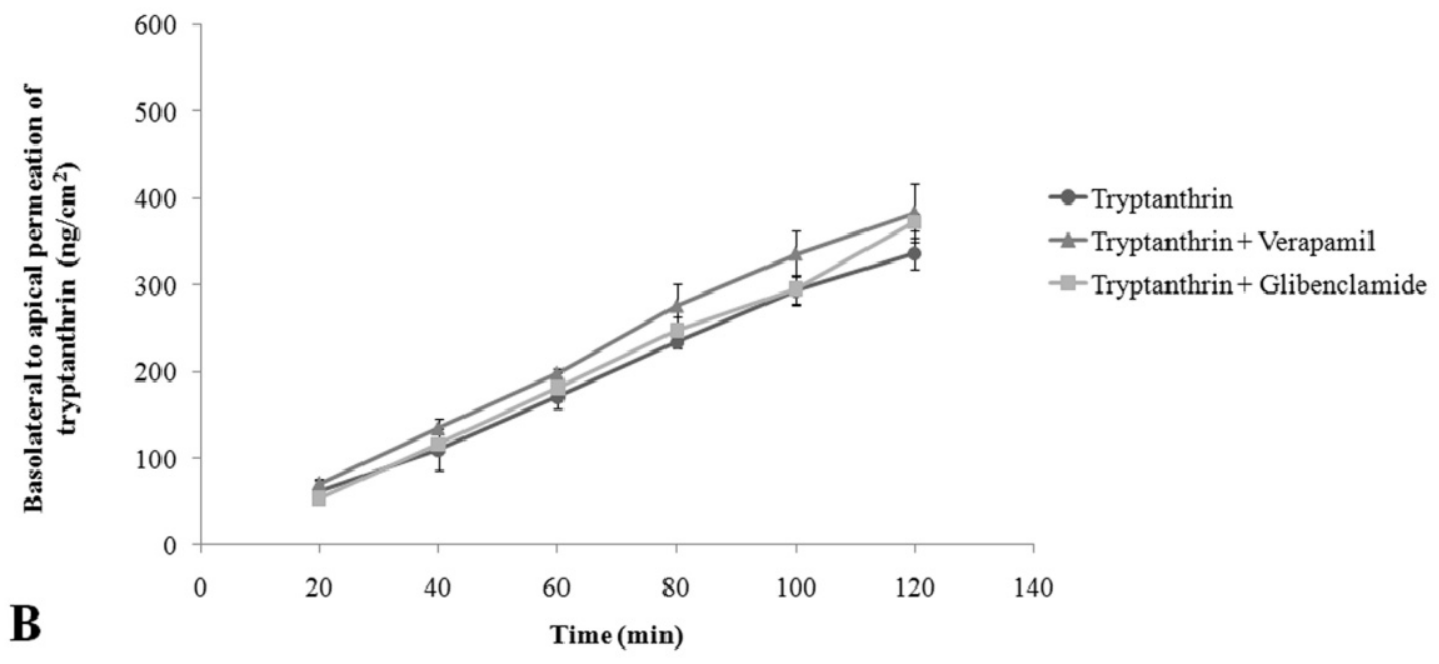

Figure 2. Effects of P-gp and MRP2 inhibitors on tryptanthrin permeation across the Caco-2 cell monolayers. Apical to basolateral (A) and basolateral to apical (B) permeation of tryptanthrin $(4 \mu \mathrm{M})$ was investigated in the presence and absence of verapamil $(100 \mu \mathrm{M})$ or glibenclamide $(100 \mu \mathrm{M})$. Each point represents the mean \pm S.D. for at least three monolayers.

${ }^{* *} P<0.05,^{* * *} P<0.01$ 
Table 1. Permeability of tryptanthrin in Caco-2 cell monolayers.

\begin{tabular}{cccc}
\hline $\begin{array}{c}\text { Tryptanthrin } \\
(\mu \mathrm{M})\end{array}$ & $\mathrm{P}_{\text {app }(\mathrm{AP} \rightarrow \mathrm{BL})}\left(\mathrm{cm} / \mathrm{s} \times 10^{-6}\right)$ & $\mathrm{P}_{\text {app }(\mathrm{BL} \rightarrow \mathrm{AP})}\left(\mathrm{cm} / \mathrm{s} \times 10^{-6}\right)$ & $\mathrm{P}_{\text {app }(\mathrm{BL} \rightarrow \mathrm{AP})} / \mathrm{P}_{\text {app }(\mathrm{AP} \rightarrow \mathrm{BL})}$ Ratio \\
\hline 0.8 & $(\mathrm{Mean} \pm \mathrm{SD})$ & $(\mathrm{Mean} \pm \mathrm{SD})$ & 0.65 \\
4 & $69.46 \pm 14.27$ & $45.32 \pm 2.99$ & 0.77 \\
20 & $61.38 \pm 2.91$ & $47.31 \pm 1.01$ & 0.86 \\
\hline
\end{tabular}

Caco-2 cells were incubated at $37{ }^{\circ} \mathrm{C}$ for $2 \mathrm{~h}$ with tryptanthrin added either to the apical or basolateral side of the cell monolayers. Data represents the mean \pm S.D. of three monolayers $(n=3)$.

Table 2. Effect of P-gp and MRP2 inhibitors on transport of tryptanthrin across Caco-2 cell monolayers

\begin{tabular}{|c|c|c|c|}
\hline & $\begin{array}{c}\mathrm{P}_{\text {app }(\mathrm{AP} \rightarrow \mathrm{BL})}\left(\mathrm{cm} / \mathrm{s} \times 10^{-6}\right) \\
(\mathrm{Mean} \pm \mathrm{SD})\end{array}$ & $\begin{array}{c}\mathrm{P}_{\mathrm{app}(\mathrm{BL} \rightarrow \mathrm{AP})}\left(\mathrm{cm} / \mathrm{s} \times 10^{-6}\right) \\
(\mathrm{Mean} \pm \mathrm{SD})\end{array}$ & $\begin{array}{c}\mathrm{P}_{\mathrm{app}(\mathrm{BL} \rightarrow \mathrm{AP})} / \\
\mathrm{P}_{\mathrm{app}(\mathrm{AP} \rightarrow \mathrm{BL})} \text { Ratio }\end{array}$ \\
\hline Tryptanthrin $(4 \mu \mathrm{M})$ & $61.38 \pm 2.91$ & $47.31 \pm 1.01$ & 0.77 \\
\hline Tryptanthrin $(4 \mu \mathrm{M})+$ Verapamil $(100 \mu \mathrm{M})$ & $61.19 \pm 3.75$ & $53.42 \pm 6.57$ & 0.87 \\
\hline Tryptanthrin $(4 \mu \mathrm{M})+$ Glibenclamide $(100 \mu \mathrm{M})$ & $38.39 \pm 5.30^{* * *}$ & $52.34 \pm 2.86$ & 1.36 \\
\hline \multicolumn{4}{|c|}{$\begin{array}{l}\text { Caco-2 cells were incubated at } 37^{\circ} \mathrm{C} \text { for } 2 \mathrm{~h} \text { with tryptanthrin added either to the apical or basolateral side of the cell } \\
\text { monolayers. Verapamil or glibenclamide was added to both the apical and basolateral sides. Data represents the mean } \pm \\
\text { S.D. of three monolayers }(\mathrm{n}=3 \text { ). } \\
{ }^{* * *} \text { Significantly different from control with } P<0.01\end{array}$} \\
\hline
\end{tabular}

Effects of Tryptanthrin on the P-gp-mediated Transport of Digoxin and the MRP2-mediated Transport of Pravastatin Sodium in Caco-2 Cell Monolayers

To evaluate the effect of tryptanthrin on the function of P-gp or MRP2, an efflux transport assay of digoxin or pravastatin sodium was performed in the presence of tryptanthrin. The concentrations of $5 \mu \mathrm{M}$ digoxin and $0.5 \mathrm{mM}$ pravastatin sodium in the transport assays were chosen according to the literatures (19-20). Efflux $\mathrm{P}_{\text {app }}$ coefficients of digoxin and pravastatin sodium were obtained in the presence vs. absence of tryptanthrin. The $\mathrm{P}_{\text {app }}$ of each group was calculated and listed in Table 3. Compared to those from the assays in the absence of tryptanthrin, the efflux $\mathrm{P}_{\text {app }}$ $(\mathrm{BL} \rightarrow \mathrm{AP})$ of both digoxin and pravastatin sodium was significantly decreased to more than $30 \%$ in the presence of tryptanthrin $(P<0.01)$.

In addition, the time courses of pravastatin transport assays in the presence and absence of tryptanthrin were performed and their results were shown in Figure 3. Compared to those in the absence of the tryptanthrin (solid circles) the efflux permeation of pravastatin sodium in the presence of tryptanthrin (solid squares) were gradually reduced over the time and reached more than $30 \%$ reduction at $2 \mathrm{~h}$. The similar results of the P-gp-mediated digoxin efflux inhibited by tryptanthrin were presented in Figure 4. These results indicated that tryptanthrin was an inhibitor of the MRP2 and the P-gp through reducing the efflux transport of their substrates. 


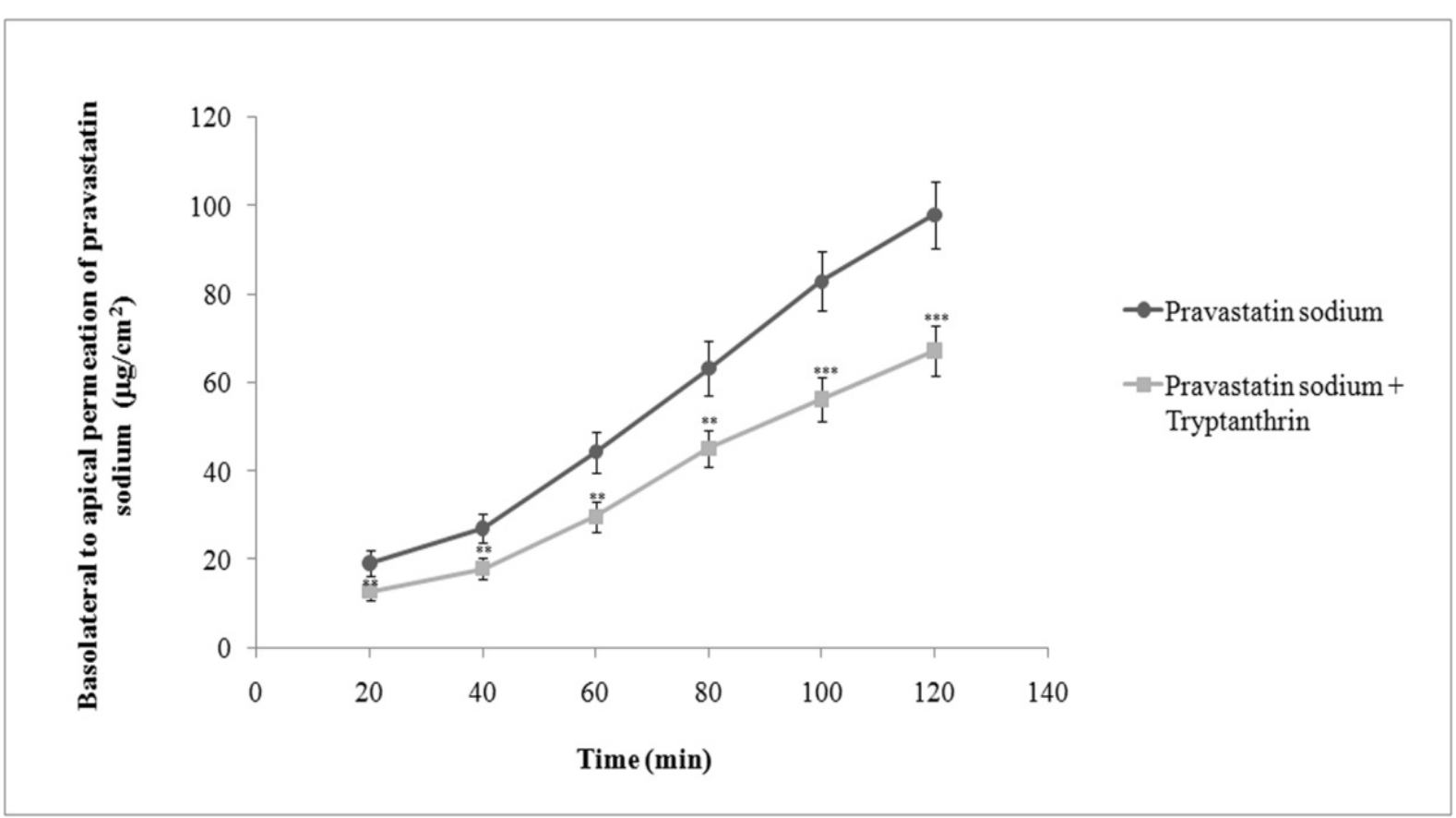

Figure 3. Inhibition of MRP2-mediated pravastatin sodium efflux by tryptanthrin across the Caco-2 cell monolayers. Basolateral to apical permeation of pravastatin sodium $(0.5 \mathrm{mM})$ was investigated in the presence and absence of tryptanthrin $(4 \mu \mathrm{M})$. Each point represents the mean \pm S.D. for at least three monolayers. ${ }^{* *} P<0.05,{ }^{* * *} P<0.01$

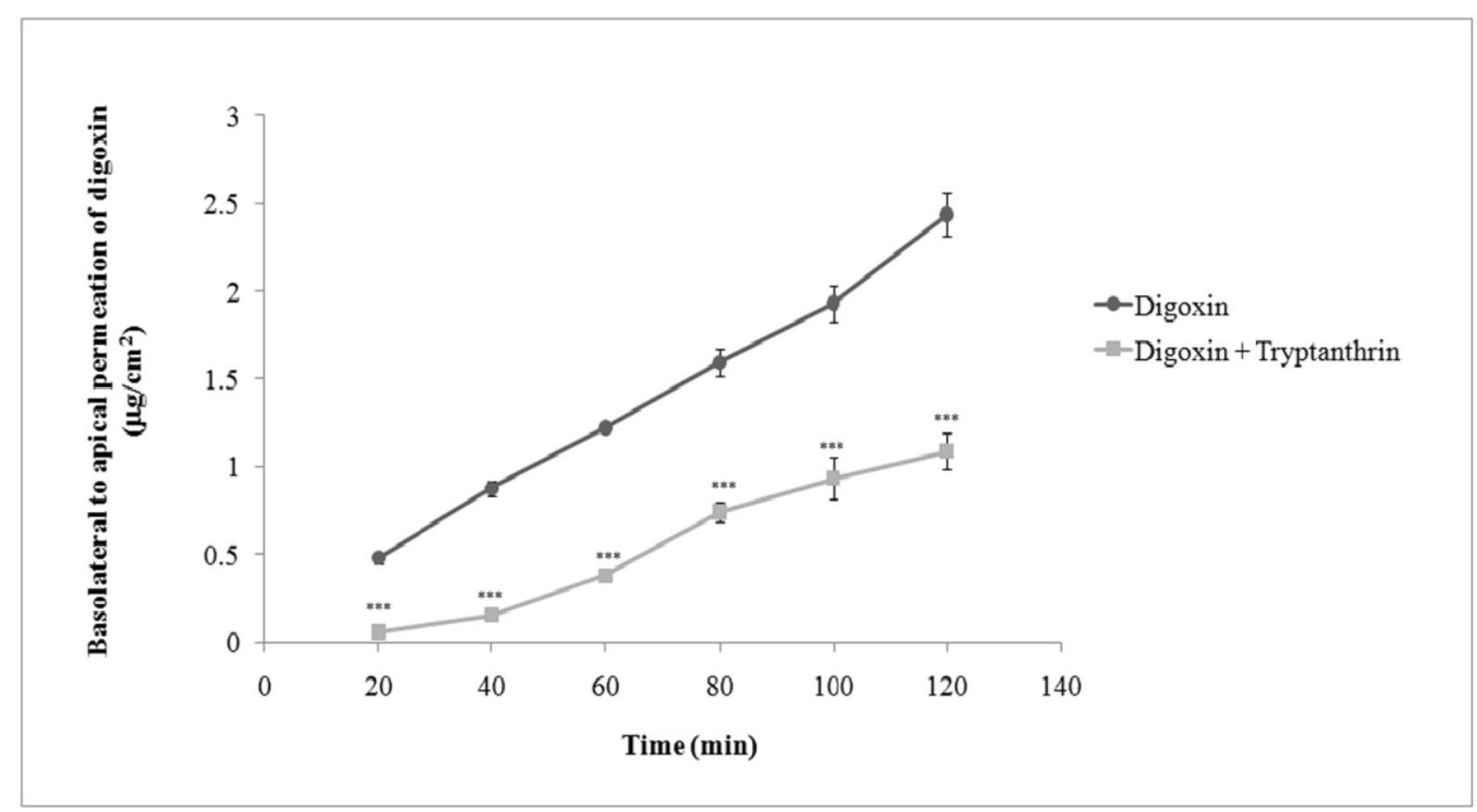

Figure 4. Inhibition of P-gp-mediated digoxin efflux by tryptanthrin across the Caco-2 cell monolayers. Basolateral to apical permeation of digoxin $(5 \mu \mathrm{M})$ was investigated in the presence and absence of tryptanthrin $(4 \mu \mathrm{M})$. Each point represents the mean \pm S.D. of at least three monolayers. ${ }^{* * *} P<0.01$ 


\section{Effect of Tryptanthrin on MDR1 and MRP2 Expression}

To address whether tryptanthrin affects the P-gp-mediated transport of digoxin and MRP2-mediated transport of pravastatin sodium via regulating the expression of these transporters, the mRNA expression of MDR1 and MRP2 genes in the Caco-2 cells, cultivated in the presence of tryptanthrin, was evaluated by RT-PCR. The Caco-2 cells were treated with $4 \mu \mathrm{M}$ tryptanthrin for up to $4 \mathrm{~h}$, and then the mRNA of MDR1 and MRP2 was isolated for RT-PCR analysis. As shown in Figure 5, the expression levels of MDR1 or MRP2 genes from the cells treated with tryptanthrin were comparable to those from the untreated cells or vehicle control. These results suggested that the expression of MDR1 and MRP2 remained the same during the transport assays.

\section{DISCUSSION}

Although tryptanthrin has been extensively studied for its multiple medical activities since 1990s, there is lack of comprehending information regarding its pharmacokinetic properties. This study represents the first investigation of the intestinal absorption and transport characteristics of tryptanthrin using Caco-2 cell monolayers, a well-established in vitro model.

Our results showed that both the influx and efflux transport of tryptanthrin were concentration-independent (Table 1), suggesting that passive diffusion is the dominant transport process for tryptanthrin in Caco-2 cell monolayers. The absorptive $\mathrm{P}_{\mathrm{app}}$ of tryptanthrin was calculated to be $(61.38 \pm 2.91) \times 10^{-6} \mathrm{~cm} / \mathrm{s}$, whereas the secretory $\mathrm{P}_{\text {app }}$ was $(47.31 \pm 1.01) \times 10^{-6} \mathrm{~cm} / \mathrm{s}$. These values are nearly fivefold higher than the threshold value $\left(1 \times 10^{-5} \mathrm{~cm} / \mathrm{s}\right)$ suggested for poorly absorbed compounds (21). The absorptive $\mathrm{P}_{\text {app }}$ was 1.3 times higher than the efflux $\mathrm{P}_{\text {app }}$, showing that absorptive transport was preponderant. These results indicate that tryptanthrin is well absorbed and the main efflux transporters probably do not participate in its transport across Caco- 2 cell monolayers. These results were further confirmed by the observation that the efflux transporter P-gp and MRP2 inhibitors, verapamil and glibenclamide, had no inhibitory effect on the efflux of tryptanthrin transport (Table 2, Figure 2B).

However, the uptake transport of tryptanthrin was significantly inhibited by glibenclamide (Table 2, Figure $2 \mathrm{~A}$ ), which is the most commonly used inhibitor (22-23). Given the fact that glibenclamide is not a specific inhibitor of the MRP2, the observed inhibitory effect of glibenclamide might result from its inhibition of other uptake transporters. In future studies, a specific MRP1 inhibitor should be applied. It was reported that the Caco-2 cell basolateral transporters MRP1, MRP3, and MRP5 are responsible for drug uptake,

(A)
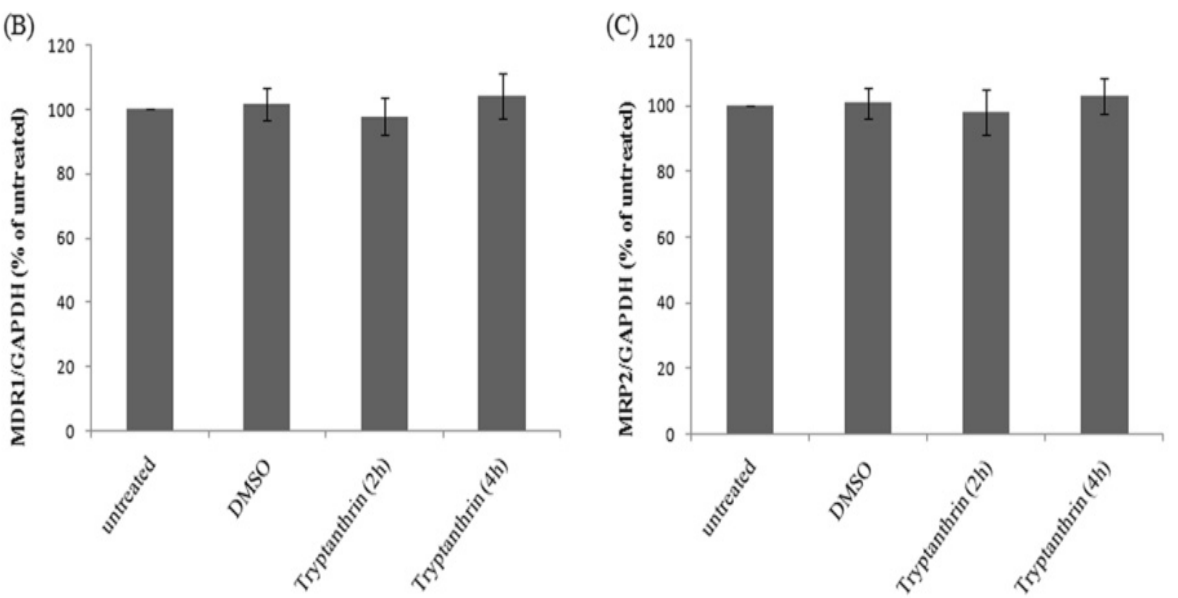

Figure 5. MDR 1 and MRP2 mRNA levels in the Caco-2 cells exposed to tryptanthrin (4 $\mu \mathrm{M})$ for $2 \mathrm{~h}, 4 \mathrm{~h}, \mathrm{DMSO}(0.1 \%$, $\mathrm{v} / \mathrm{v}$, vehicle) or culture medium (untreated, control) (A). GAPDH was used as the internal standard. MDR1 (B) and MRP2 (C) mRNA levels were quantified by densitometry in relation to GAPDH. Data were expressed as mean \pm SD from three independent experiments. 
whereas the apical transporters P-gp and MRP2 regulate drug efflux (24). Previous literature has also shown that glibenclamide could inhibit the activity of both MRP2 and MRP1 in GLC4/Sb30 cells (18). Our study showed that in the efflux direction $(\mathrm{BL} \rightarrow \mathrm{AP})$, the $\mathrm{P}_{\text {app }}$ of tryptanthrin remained almost constant when glibenclamide (100 $\mu \mathrm{M})$ was added, suggesting that MRP2 did not participate in the efflux transport of tryptanthrin. If the MRP1 played a key role in the uptake of tryptanthrin in Caco-2 cells, presumably, glibenclamide decreased tryptanthrin uptake by inhibiting the activity of MRP1.

The evaluation of the potential effect of a compound on the function of an efflux transporter usually only investigates the change in efflux transport of substrate. For instance, to find the effect of pravastation on MRP2 mediated cyclosporin A transport in Caco-2 monolayer, only efflux transport assay of cyclosporin $\mathrm{A}$ in the presence of pravastation was performed (19). Herein, to address whether tryptanthrin is a potential inhibitor of P-gp and MRP2 in Caco-2 cell monolayers, efflux transport assays of P-gp substrate, digoxin, and MRP2 substrate, pravastatin sodium were performed in the presence of tryptanthrin. As shown in Table 3 both the efflux $\mathrm{P}_{\text {app }(\mathrm{BL} \rightarrow \mathrm{AP})}$ values of digoxin and pravastatin sodium were decreased in the presence of tryptanthrin. However, the presence of tryptanthrin did not downregulate the expression of P-gp or MRP2 genes over either $2 \mathrm{~h}$ or $4 \mathrm{~h}$ period of the transport assays. Therefore, our results suggested that tryptanthrin directly inhibited the functional activities of these two transporters. Recently, it was reported that tryptanthrin could reverse doxorubicin resistance in MCF-7 cells by suppressing MDR1 gene expression and P-gp production (15). Similarly, our findings showed that tryptanthrin could directly inhibit the activity of P-gp and MRP2.

It is worth to notice that in the previous study tryptanthrin downregulated the MDR1 gene in breast cancer MCF-7 cells (15), but in the present study tryptanthrin did not show the downregulation of the MDR1 gene expression over 2-4hrs. This discrepancy is due to the different experimental designs between the two studies. In Yu ST's report, the MCF-7/adr cells were seeded into six-well plates at a density of $2 \times 10^{5} /$ well in the presence of tryptanthrin at $10^{-6} \mathrm{M}$ for 5 days. On the fifth day, the expression MDR1 gene and protein in the cells was decreased. In addition, they found that tryptanthrin down-regulated MDR1 expression by interfering the binding of CAAT motif to nuclear transcription factors (15). In the present study, because the tryptanthrin treatment was only lasted for 2 hours, tryptanthrin did not show any downregulation of the MDR1 gene expression.

It was reported that the minimum inhibitory concentration (MIC, 2-4 $\mu \mathrm{M}$ ) of tryptanthrin was efficient against multiple drug-resistant (MDR) tuberculosis strains (11), and within the concentration range of $0.95-5 \mu \mathrm{M}$ tryptanthrin showed effective in vitro antitumor activity against numerous of cancer cell lines, including renal A498, ovarian SKOV3, melanoma M14, colon SW620, and lung H522 (8). Therefore, the concentration of tryptanthrin $(0.8-20 \mu \mathrm{M})$ was chosen for the present transport study.

Table 3. Effect of tryptanthrin on efflux transport of P-gp or MRP2 substrate across Caco-2 cell monolayers

\begin{tabular}{lc}
\hline & $\begin{array}{c}\mathrm{P}_{\text {app }(\mathrm{BL} \rightarrow \mathrm{AP})}\left(\mathrm{cm} / \mathrm{s} \times 10^{-6}\right) \\
(\mathrm{Mean} \pm \mathrm{SD})\end{array}$ \\
\hline Digoxin $(5 \mu \mathrm{M})$ & $62.80 \pm 3.80$ \\
Digoxin $(5 \mu \mathrm{M})+$ Tryptanthrin $(4 \mu \mathrm{M})$ & $43.59 \pm 2.93^{* * *}$ \\
Pravastatin sodium $(0.5 \mathrm{mM})$ & $79.33 \pm 4.80$ \\
Pravastatin sodium $(0.5 \mathrm{mM})+$ Tryptanthrin $(4 \mu \mathrm{M})$ & $46.69 \pm 4.61^{* * *}$ \\
\hline Caco-2 cells were incubated at $37^{\circ} \mathrm{C}$ for $2 \mathrm{~h}$ with digoxin or pravastatin sodium added to the basolateral side of the \\
cell monolayers. Tryptanthrin was added to both the apical and basolateral sides. Data represents the mean \pm S.D. of \\
three monolayers $(\mathrm{n}=3)$.
\end{tabular}


For further investigation, a series of concentrations of tryptanthrin would be set up for transport assays in Caco-2 cell monolayers to determine whether the tryptanthrin effect on P-gp and MRP2 is concentration dependent. It is known that the overexpression of P-gp and MRP2 in tumor cells can lead to drug resistance and chemotherapeutic failure (25-26). Thus, it seems that tryptanthrin might be a potential adjuvant agent for chemotherapy targeting these particular tumor cells.

In conclusion, tryptanthrin was well absorbed across the Caco-2 monolayers, and its absorptive and efflux transport were both dominated by passive diffusion. Tryptanthrin was not a substrate of P-gp or MRP2, but a potential inhibitor of P-gp and MRP2. This study provides useful information for characterizing the pharmacokinetic properties of tryptanthrin.

\section{ACKNOWLEDGEMENTS}

The authors thank Dr. J. L. Liu from The College of Life Sciences, Northwest University, Xi'an, China for the generous supply of tryptanthrin. This work was supported by the Severe Infectious Disease Project of China (Grant no. 2008ZX10003-006-2). We thank for Dr. Y. Hefner (1278 Avenida Miguel, Encinitas, CA 02024, U.S.A.) for helpful discussion and critical reading as well as editing this manuscript.

\section{REFERENCES}

1. Honda G, Tabata M. Isolation of antifungal principle tryptanthrin, from Strobilanthes cusia O. Kuntze. Planta Med, 1979; 36:85-90.

2. Bhattacharjee AK, Skanchy DJ, Jennings B, Hudson $\mathrm{TH}$, Brendle JJ, Werbovetz KA. Analysis of stereoelectronic properties, mechanism of action and pharmacophore of synthetic indolo[2,1-b]quinazoline-6,12-dione derivatives in relation to antileishmanial activity using quantum chemical, cyclic voltammetry and 3-D-QSAR CATALYST procedures. Bioorg Med Chem, 2002; 10:1979-89.

3. Scovill J, Blank E, Konnick M, Nenortas E, Shapiro T. Antitrypanosomal activities of tryptanthrins. Antimicrob Agents Chemother, 2002; 46:882-3.

4. Pitzer KK., Scovill JP, Kyle DE, Gerena L. Indolo[2,1-B] quinazole-6,12-dione antimalarial compounds and methods of treating malaria therewith. U.S. Patent 6531487, 2003.

5. Danz H, Stoyanova S, Wippich P, Brattström A, Hamburger M. Identification and isolation of the cyclooxygenase-2 inhibitory principle in Isatis tinctoria. Planta Med, 2001; 67:411-6.

6. Danz H, Stoyanova S, Thomet OA, Simon HU, Dannhardt G, Ulbrich H, Hamburger M. Inhibitory activity of tryptanthrin on prostaglandin and leukotriene synthesis. Planta Med, 2002; 68:875-80.

7. Ishihara $\mathrm{T}$, Kohno K, Ushio S, Iwaki K, Ikeda M, Kurimoto M. Tryptanthrin inhibits nitric oxide and prostaglandin E(2) synthesis by murine macrophages. Eur J Pharmacol, 2000; 407:197-204.

8. Sharma VM, Prasanna P, Seshu KV, Renuka B, Rao CV, Kumar GS, Narasimhulu CP, Babu PA, Puranik RC, Subramanyam D, Venkateswarlu A, Rajagopal S, Kumar KB, Rao CS, Mamidi NV, Deevi DS, Ajaykumar R, Rajagopalan R. Novel indolo[2,1-b]quinazoline analogues as cytostatic agents: synthesis, biological evaluation and structure-activity relationship. Bioorg Med Chem Lett, 2002; 12:2303-7.

9. Kimoto T, Hino K, Koya-Miyata S, Yamamoto Y, Takeuchi M, Nishizaki Y, Micallef MJ, Ushio S, Iwaki K, Ikeda M, Kurimoto M. Cell differentiation and apoptosis of monocytic and promyelocytic leukemia cells (U-937 and HL-60) by tryptanthrin, an active ingredient of Polygonum tinctorium Lour. Pathol Int, 2001; 51:315-25.

10. Koya-Miyata S, Kimoto T, Micallef MJ, Hino K, Taniguchi M, Ushio S, Iwaki K, Ikeda M, Kurimoto M. Prevention of azoxymethane-induced intestinal tumors by a crude ethyl acetate-extract and tryptanthrin extracted from Polygonum tinctorium Lour. Anticancer Res, 2001; 21:3295-300.

11. Mitscher LA, Baker W. Tuberculosis: a search for novel therapy starting with natural products. Med Res Rev, 1998; 18:363-74.

12. Global Alliance for TB Drug Development. "Background":

$<$ http://www.tballiance.org/new/portfolio/html-portfo lio-item.php?id=29.>, cited 7 April, 2011.

13. Wang SW, Yang Q, Wang JB, Xie YH, Miao S, Sun JY. The preparation and application of a series tryptanthrin formulations. Chinese Patent. 200810017395.0, 2008.

14. Shah P, Jogani V, Bagchi T, Misra A. Role of Caco-2 cell monolayers in prediction of intestinal drug absorption. Biotechnol Prog, 2006; 22:186-98.

15. Yu ST, Chen TM, Tseng SY, Chen YH. Tryptanthrin inhibits MDR1 and reverses doxorubicin resistance in breast cancer cells. Biochem Biophys Res 
Commun, 2007; 358:79-84.

16. Jedlicka A, Grafnetterová T, Miller V. HPLC method with UV detection for evaluation of digoxin tablet dissolution in acidic medium after solid-phase extraction. J Pharm Biomed Anal, 2003; 33:109-15.

17. Li X, Otter K, Ziegler A. Determination of pravastatin in rat liver by RP-HPLC. Yao Xue Xue Bao, 2001; 36:123-6.

18. Payen L, Delugin L, Courtois A, Trinquart Y, Guillouzo A, Fardel O. The sulphonylurea glibenclamide inhibits multidrug resistance protein (MRP1) activity in human lung cancer cells. $\mathrm{Br} \mathrm{J}$ Pharmacol, 2001; 132:778-84.

19. Kato R, Nishide M, Kozu C, Iwamoto A, Urashima K, Suzuki K, Ijiri Y, Hayashi T, Tanaka K. Is cyclosporine A transport inhibited by pravastatin via multidrug resistant protein 2? Eur J Clin Pharmacol, 2010; 66:153-158.

20. Xin HW, Schwab M, Klotz U. Transport studies with 5-aminosalicylate. Eur J Clin Pharmacol, 2006; 62:871-875.

21. Rubas W, Jezyk N, Grass GM. Comparison of the permeability characteristics of a human colonic epithelial (Caco-2) cell line to colon of rabbit, monkey, and dog intestine and human drug absorption. Pharm Res, 1993; 10:113-8.
22. Payen L, Sparfel L, Courtois A, et al. The drug efflux pump MRP2: Regulation of expression in physiopathological situations and by endogenous and exogenous compounds. Cell Biol Toxicol, 2002; 18:221-233

23. Payen L, Delugin L, Courtois A, et al. The sulphonylurea glibenclamide inhibits multidrug resistance protein (MRP1) activity in human lung cancer cells. Br J Pharmacol, 2001; 132:778-784.

24. Prime-Chapman HM, Fearn RA, Cooper AE, Moore $\mathrm{V}$, Hirst BH. Differential multidrug resistance-associated protein 1 through 6 isoform expression and function in human intestinal epithelial Caco-2 cells. J Pharmacol Exp Ther, 2004; 311:476-84.

25. Germann UA, Pastan I, Gottesman MM. P-glycoproteins: mediators of multidrug resistance. Semin Cell Biol, 1993; 4:63-76.

26. Cui Y, König J, Buchholz JK, Spring H, Leier I, Keppler D. Drug resistance and ATP-dependent conjugate transport mediated by the apical multidrug resistance protein, MRP2, permanently expressed in human and canine cells. Mol Pharmacol, 1999; 55:929-37. 